\title{
O processo de pacificação nas favelas cariocas: Elementos para uma crítica
}

\author{
The social pacification process in the favelas of Rio de Janeiro: Elements for criticism \\ El proceso de pacificación em las favelas de Río de Janeiro: Elementos para una crítica
}

Recebido: 05/01/2021 | Revisado: 06/01/2021 | Aceito: 09/01/2021 | Publicado: 10/01/2021

Paloma Henriques Maricato

ORCID: https://orcid.org/0000-0001-9505-3137

Universidade Federal do Rio de Janeiro, Brasil

E-mail: palomamaricato@yahoo.com.br

\begin{abstract}
Resumo
O presente artigo é resultado do interesse em analisar como é pensada a segurança pública no Estado do Rio de Janeiro a partir da implantação das Unidades de Polícia Pacificadora (UPPs) em 2008, marcado por uma "nova forma" de intervenção policial nos espaços populares. Tem como objetivo analisar o impacto das UPPs nos espaços favelados, marcado pelo aumento do poder punitivo e da aceitação da sociedade no recrudescimento de políticas autoritárias, historicamente marcado pela militarização da segurança pública nos territórios populares. A partir do aprofundamento das leituras e a análise do desenvolvimento dessa "nova proposta" de segurança pública observa-se que as UPPs são assinaladas pela ocupação militarizada das favelas e disciplinamento dos corpos. Além disso, busca compreender o fenômeno da violência nesses espaços e a necessidade aparente de um agente externo que fiscalize e regule as ações dessa população. Foram utilizados os seguintes instrumentos metodológicos: levantamento e leitura sobre o tema, artigos de jornais e revistas de grande circulação e especializadas.
\end{abstract}

Palavras-chave: Segurança pública; Cidade; Território.

\begin{abstract}
This article is the result of the interest in analyzing how public security in the State of Rio de Janeiro is thought of from the implementation of Pacifying Police Units (UPPs) in 2008, stating a new way of police intervention in popular communities. It aims at analyzing the impact of UPPs in the slums and favelas, marked by the raise of punishing power and the acceptance from the society of the implementation of authoritarian policies, historically stated by the advance of military power over public security in popular areas. From the advance of readings and development analysis of this "new proposal" of public security we can notice that the UPPs are characterized by the military domination of poor communities and favelas as well as the disciplining of their occupants. Moreover, it aims at understanding the phenomenon of violence in such areas and the apparent need of an external agent to monitor and restrain the actions of their inhabitants. It was taken the following methodological instruments: brainstorming and reading of the theme, articles from eminent popular specialized newspapers and magazines.
\end{abstract}

Key-words: Public security; City; Areas.

\section{Resumen}

Este artículo resulta del interés por analizar cómo se piensa la seguridad pública en el Estado de Río de Janeiro luego del despliegue de las Unidades Policiales Pacificadoras (UPPs) en 2008, marcado por una "nueva forma" de intervención policial en los espacios populares. Tiene como objetivo analizar el impacto de las UPPs en los espacios de favelas, marcado por el aumento del poder punitivo y de la aceptación de la sociedad en el auge de las políticas autoritarias, históricamente marcado por la militarización de la seguridad pública en los territorios populares. A partir de la profundización de las lecturas y el análisis del desarrollo de esta "nueva propuesta" de seguridad pública, se observa que las UPPs están marcadas por la ocupación militarizada de las favelas y la acción disciplinaria de los cuerpos. Además, busca comprender el fenómeno de la violencia en estos espacios y la aparente necesidad de un agente externo que fiscalice y regule las acciones de esta población. Se utilizaron los siguientes instrumentos metodológicos: investigación y lectura sobre el tema, artículos en periódicos y revistas de gran circulación y especializadas.

Palavras-clave: Seguridad pública; Ciudad; Territorio.

\section{Introdução}

Este texto toma como base parte da minha dissertação e se propõe a discutir a ação das políticas criminais neoliberais, baseadas nos programas da "lei e ordem" com a adoção de um modelo disciplinar que se dirige não apenas a uma pessoa considerada culpada, mas passam a ser direcionadas aos grupos sociais tidos como "perigosos" suspeito de ameaçar o status 
quo. Tais grupos são tidos como transgressores, unicamente pela sua condição de classe subalterna. Para tanto, devem ser vigiados, controlados e punidos. Assim, a política criminal ganha cada vez mais espaço com políticas de disciplinares de exclusão e segregação. De um lado, tem-se o Estado de Direito e de outro uma resposta penalizadora do Estado para as questões sociais.

Cabe também pontuar a distinção entre a política de segurança pública, que se configura como uma prática de "guerra contra o crime", onde há um inimigo a combater, na qual as práticas de policiamento tem base no eficientismo penal que se expressa no direito penal máximo. E, as políticas públicas de segurança, que se caracterizam com a integração de diferentes serviços públicos, como educação, habitação, transporte, lazer, trabalho e saúde. Neste caso, as propostas de ação policial, estão baseadas na noção do garantismo penal e do direito penal mínimo, onde prevalece os princípios de direitos humanos (Dornelles, 2001).

No que se refere a território, baseio-me no conceito desenvolvido por Milton Santos: "um conjunto de lugares e o espaço nacional como um conjunto de localizações; temos que estar sempre mudando, não obstante o lugar fique o mesmo, em vista do constante rearranjo de valores atribuídos a cada lugar e às atividades presentes" (Santos, 1996 apud Malaguti, 2011, p.1). O autor entende que cada lugar está sempre modificando de significação, graças ao movimento social: a cada instante as frações da sociedade que lhe cabem não são as mesmas.

Malaguti, referenciando Milton Santos, descreve que na geografia das desigualdades a definição de território é política: "trata-se de território usado, espaço banal aonde se podem propor dois tipos de espaços: 'os espaços que mandam e os espaços que obedecem, gerados pelo permanente embate entre o par dialético abundância-escassez"” (2011, p.2).

Além desses dois pares dialéticos, Maria Adélia nos aponta mais dois para caracterizar o território usado:

"Densidade-rarefação e fluidez-viscosidade. 'O espaço, por sua vez, também apresenta duas características que se apresentam dialeticamente: rapidez e lentidão, luminosidade e opacidade. Tais características é que geram as novas lógicas na relação centro-periferia, conceitos caros à geografia e revisitados pela obra miltoniana'. A ideia de densidade nos demonstra, por exemplo, maiores ou menores concentrações de serviços, informações e também 'a maior ou menor densidade de leis, normas, regras reguladoras da vida coletiva', tudo isso 'a serviço das forças hegemônicas e do Estado' definindo realidades espaciais, aprofundando desigualdades." (Souza, 2003, Apud Malaguti, 2011, p.2).

É necessário nos atentarmos para as modificações dadas nos territórios populares, entendendo a produção dessas transformações nesse novo contexto de cidade-empresa, no qual aprofunda as desigualdades territoriais e modifica tais espaços a partir dos interesses da classe dominante.

Cabe ressaltar que o pano de fundo para a implantação das UPPs está relacionado diretamente às transformações processadas na cidade com o novo contexto de empresariamento urbano e os diferentes interesses em jogo para a construção da recuperação da imagem de cidade, bem como o papel das UPPs nesse novo contexto.

Dessa forma, o programa das UPPs, iniciado em dezembro de 2008, busca diminuir a sensação de insegurança, eliminando os conflitos armados em áreas de alta renda que tanto atraem os consumidores estrangeiros.

Sendo assim, é necessário que as UPPs sejam analisadas dentro de um projeto maior que envolve interesses do capital. Sassen aponta que "a combinação da dispersão espacial e da integração mundial tem contribuído no desempenho de um papel estratégico das maiores cidades na atual fase da economia mundial” (Sassen, 1993, p.188). Há uma desconcentração espacial da produção com o avanço da tecnologia e uma integração concomitante de diversas atividades. Contudo, as condições distintas sob as quais tais facilidades são disponíveis promovem a centralização de usuários avançados nos centros de telecomunicações mais desenvolvidos. Sendo assim, a tendência é que as empresas maiores estejam concentradas em cidades maiores e que haja desenvolvimento de infraestruturas em tais cidades. Segundo a autora, o novo modelo de gestão urbana estaria fortemente vinculado à produção de representações e práticas que transformam a cidade em mercadoria. 


\section{Metodologia}

A metodologia de pesquisa adotada segue uma abordagem qualitativa e o tipo de pesquisa configura-se como um estudo bibliográfico, bem como pesquisa documental sobre o tema com a utilização de reportagens jornalísticas. De acordo com Minayo (2011), a pesquisa qualitativa responde a questões particulares e trabalha com o universo dos significados, dos motivos, das crenças, dos valores e das atitudes. Tais fenômenos são entendidos para a autora como parte da realidade social, uma vez que o Homem se distingue não apenas pelo agir, mas por pensar sobre o que faz e por interpretar suas ações dentro da realidade vivida e partilhada.

$\mathrm{O}$ trabalho ora apresentado segue a abordagem marxista enquanto teoria, a qual considera a historicidade dos processos sociais e dos conceitos, as condições socioeconômicas de produção dos fenômenos e as contradições sociais.

A pesquisa bibliográfica aprofundou em alguns autores, tais como: Sanchez e Sassen os quais trabalham com a discussão da nova forma de produção do espaço urbano a partir do desenvolvimento econômico, exigindo que tais espaços assumam contornos empresariais de modo que atenda a demanda mercadológica; aprofunda na análise de Mészáros que trata da inversão entre causas e efeitos, bem como a incapacidade do sistema capitalista de corrigir integralmente os efeitos de seus danos, sem atingir a origem do problema; Dá ênfase na leitura de Foucault sobre disciplinamento dos corpos e Zaffaroni que trata do exercício do poder punitivo.

\section{Resultados e Discussões}

\subsection{Entre a aparência e a essência: As UPPs como um "novo" dispositivo disciplinar?}

O projeto das UPPs não é algo novo na história, este faz parte de um arsenal de intervenções urbanas previstas para regiões ocupadas militarmente no mundo a partir de tecnologias, programas e políticas norte-americanas que vão do Iraque à Palestina. As UPPs, sustentada pela afirmação de sociólogos comprometidos com esse projeto basearam-se no modelo de Medellín, onde Governador e Prefeito se apropriaram do projeto e o replicou para o Rio de Janeiro. Trata-se como assinala Malaguti (2011) de uma "fórmula" - já fracassada - pronta na "luta contra o crime".

As intensas campanhas de pânico social, analisadas por Malaguti (2003), produzem na sociedade uma internalização cada vez maior do autoritarismo, apoiando dessa forma, projetos de ocupação militarizada como o que está posto. A ocupação de algumas favelas do Rio desenhou-se em forma de guerra estabelecendo uma gestão policial e policialesca da vida cotidiana dos pobres dessas localidades. Há um deslocamento de atenção do Estado no trato com a população pauperizada de uma política de assistência social para uma gestão penal da pobreza (Malaguti, 2011).

Assim como aponta Wacquant (2007), com o aprofundamento das desigualdades sociais, desenvolve-se um processo de "criminalização das consequências da miséria de Estado". Em detrimento dos investimentos em políticas públicas que visem o bem estar da população, esse novo modo de enfrentamento à pobreza, abstêm-se de enfrentar as causas econômicas da pauperização. Assim, desenvolve-se um Estado disciplinar que busca o controle das "classes perigosas", bem como transformam as políticas sociais em instrumento de vigilância e controle da população empobrecida, com ações de prevenção à possível atuação desviante, com vistas a neutralização desses grupos.

A partir da análise do autor, observamos que o processo de "pacificação" baseia-se numa gestão penal da pobreza enfocando em políticas criminais, acentuando o Estado de polícia. O que presenciamos é o controle social da classe pauperizada e uma carência no investimento em serviços públicos.

Para obter o apoio da sociedade nesse processo de implantação das UPPs, segue-se uma lógica pragmática, em que, se o referido projeto está atendendo a necessidades imediatas (?) - vale ressaltar que os objetivos oficialmente fixados por seus idealizadores estão longe de serem alcançados, tendo em vista que o controle armado desses espaços permanece refletindo no alto índice de letalidade policial, bem como no aumento do número de desaparecidos nos espaços "pacificados" - logo é 
funcional. Porém, devemos ressaltar que, conforme analisa Vázquez (1990), as coisas não apenas são e existem em si, mas também existem por sua significação prática, na medida em que satisfaçam necessidades imediatas.

De acordo com Netto (1994), a teoria, a razão e a ciência objetivam ultrapassar e superar a imediaticidade dos fenômenos. Estas devem compreender a essência dos fenômenos presentes nas complexas relações sociais que estruturam o capitalismo. Entretanto, o que temos observado de acordo com Coutinho (2010), é que há um abandono praticamente integral do terreno científico. Presencia-se o surgimento de um irracionalismo fundamentado na intuição arbitrária, valorizando o agnosticismo.

Referenciando Marx, Coutinho (2010) ressalta que é necessário questionarmos quais são os limites objetivos impostos pela vida imediata. Para o autor, a principal limitação imposta pela divisão do trabalho é a cisão entre trabalho intelectual e trabalho manual.

Lukács (1992) ressalta que a divisão social do trabalho não apenas promove essa cisão, como também provoca profundas deformações psíquicas e morais nos homens, revelando-se de diversas formas nas variadas manifestações ideológicas, culminado inevitavelmente numa cisão entre o intelecto e a vida dos sentimentos.

De acordo com Lukács, há uma fundamental ausência de relações entre pensamento e ação, entre teoria e práxis, fruto das ciências sociais modernas que se apresentam carregadas por um discurso de que os homens não conseguem mais dominar todo o campo do saber humano sem abandonar o nível científico. Dessa forma, os saberes são fragmentados, afetados pela decadência da ideologia burguesa, a qual impede que tais ciências se relacionem entre si (Lukács, 1992).

Os produtos da atividade humana revelam-se aos indivíduos como algo alheio à sua essência, marcado por uma divisão entre a práxis criadora e a existência dos homens ${ }^{1}$ e mulheres. A existência humana transforma-se num objeto “coisificado" impossibilitado de conter em si qualquer subjetividade, transformando-se num fetiche vazio (Coutinho, 2010).

Ainda com Vázquez (1990), a essência não se manifesta de maneira direta e imediata através de sua aparência. Na prática cotidiana não há um movimento de reflexão. A consciência comum pensa os atos práticos, sem mediações.

A consciência comum acredita estar numa relação direta e imediata com o mundo dos atos e objetos práticos. Suas conexões com esse mundo e consigo mesma aparecem diante dela num plano a-teórico. Não sente necessidade de rasgar a cortina de preconceitos, hábitos mentais e lugares-comuns na qual projeta seus atos práticos. Acredita viver e nisso vê uma afirmação de suas conexões com o mundo da prática - à margem de toda teoria, à margem de um raciocínio que só viria arrancar-lhe da necessidade de responder às exigências práticas, imediatas, da vida cotidiana (Vázquez, 1990).

A fala do ex secretário de segurança pública, José Mariano Beltrame, sobre a violência do tráfico nas favelas, corrobora a citação acima: "Nós só vamos mudar isso com atitude, não vai ser com conversa, com livrinho.".". Fica evidente, assim como desenvolve Zaffaroni (2007), que o exercício do poder punitivo tornou tão irracional que não tolera sequer um discurso acadêmico, uma vez que se reduz a uma mera peça publicitária. Os políticos, acrescenta o autor, deixam de buscar o melhor para se preocuparem apenas com o que pode ser transmitido de melhor, com vistas a aumentar sua clientela eleitoral. Observa-se, além do exposto, que a deformação da realidade, dinamizada na/pela ideologia dominante, permite uma aparente adesão de parte dos moradores dos bairros populares.

O discurso de Beltrame vem carregado por uma crença de que a prática explica-se por si mesma. Nesse caso, a teoria seria apenas uma sistematização da prática, como aponta Santos (2010). A autora enfatiza que "o empírico é um nível necessário do real, mas tem que ser superado pela razão" (p.19). Nesse sentido, vemos que o empírico é parte do real, porém

1 Adoto a ideia de que homens e mulheres tem um lugar de gênero distinto. Embora os autores mencionados não discutam questão de gênero, trabalhando com cidadania feminina, não posso deixar de assinalar a importância de designar os sujeitos de modo engendrado.

2 Palestra dada na Escola de Ensino Superior da Polícia Militar, em 12/07/2012. 
não apreenderemos o real em sua totalidade apenas por meio do saber empírico. Desta forma, sinalizamos que, a política de segurança pública coloca as UPPs como solução para os problemas da criminalidade, mas não foca nas estruturas sociais que geram tais problemas.

Observamos também no discurso do secretário, uma total cisão entre pensamento e ação, sem qualquer esforço no sentido de compreender a relação entre o fenômeno da violência do tráfico de drogas com os problemas econômicos postos na atualidade. Tal pensamento é fruto de um irracionalismo que apela "aos piores instintos humanos, às reservas de animalidade $\mathrm{e}$ de bestialidade que necessariamente se acumulam no homem em regime capitalista" (Lukács, 1992, p.127). O secretário trata a questão da violência como se não existisse nada além do imediato, da aparência, uma vez que busca a eficiente a partir de uma resolutividade, desprezando os processos sociais presente em todo contexto.

A aparência, segundo Santos (1997), é a não-realidade que cria obstáculos para a transparência do real. Caberia, nesse caso, a ciência identificar a aparência e ultrapassá-la desvendando a essência.

Segundo Kosik (1976), a práxis utilitária imediata e o senso comum colocam o homem em condições de manejar as situações do cotidiano, mas não proporcionam a compreensão das coisas e da realidade, não desvendam a sua essência, uma vez que esta não se dá de forma imediata. A essência é mediata aos fenômenos que se reproduzem espontaneamente no pensamento comum como realidade, sendo assim, ela se manifesta diferente daquilo que é. É necessário compreender o fenômeno para atingir sua essência. Segundo o autor, o mundo da pseudoconcreticidade "é um claro-escuro de verdade e engano" (Kosik, 1976 p.11).

Assim, buscando desvendar a essência que está por trás do projeto das UPPs, é necessário entendermos esse processo de transformação da cidade em mercadoria, cidade-empresa que passa a ser vendida na bolsa de imagens urbanas na disputa desse capital fugaz. O projeto das UPPs é parte desse novo processo de empreendedorismo urbano que precisa aparecer como único, necessário, imprescindível, um uníssono que carece muito do esplendor do Estado de polícia. (Malaguti, 2011).

\section{2 - A militarização da segurança pública.}

A relação entre população e instituição policial, quando vista a partir do legado histórico do país, permite-nos identificar que elementos característicos de nossa sociedade contemporânea sempre estiveram presentes na realidade brasileira, dentre eles o arbítrio do poder público frente aos segmentos populares. Essas características, contudo, vão se modificando de acordo com as diferentes conjunturas.

Em 1808 com a vinda da família real para o Brasil foi criada no Rio de Janeiro, a Intendência Geral de Polícia, sendo esta semelhante à estrutura do exército, tendo como função a manutenção do sossego público. Dessa Guarda Real original, derivaram as instituições policiais uniformizadas de formato militar que ainda hoje fazem o policiamento urbano no Rio de Janeiro (Bretas, 1998).

Bretas (1998), ao estudar a polícia no império afirma que os castigos aplicados aos policiais eram sempre por infrações internas, agressões a outros policiais, e não por violência cometida no serviço contra a população, que, segundo o autor, eram práticas usuais. Holloway afirma que quando confrontado com queixas da população, relativas a abusos promovidos pelos policiais, a preferência do comandante era pela proteção de seu pessoal, fazendo investigações que terminavam não comprovando nada. (Apud Bretas, 1998, p.15)

O período do Estado Novo (1937-1945), e o período da Ditadura Militar (1964-1985), foram também, significativos para formar uma polícia violenta. O fim do regime ditatorial não significou, necessariamente, em mudanças estruturais capazes de romper com as práticas autoritárias que vão se constituindo no decorrer da história.

Nesse sentido, observamos que a militarização da segurança pública não é um fato novo na historia da polícia. Assim, vemos mais uma vez uma militarização da segurança pública por meio da implantação das UPPs. 
O fato da implantação do projeto estar restrita apenas ao espaço das favelas e de algumas favelas revela o real interesse dos governantes: "a ocupação militar e verticalizada das áreas de pobreza que se localizam em regiões estratégicas aos eventos desportivos do capitalismo vídeo-financeiro." (Malaguti, 2011, p.2). Nesse sentido, a autora enfatiza que as UPPs aprofundaram as desigualdades e as segregações socioespaciais no Rio de Janeiro.

Menegat (2005) ressalta que a segregação dos territórios sempre foi uma heterotopia perseguida pela sociedade de classes. Trata-se, como assinala o autor, de uma estratégia de espacialização da dinâmica de classes. A funcionalidade ideológica dessa estratégia está na legitimidade da contraposição de uma parte à outra da sociedade, moralmente fraca, cujo peso de sua culpa pela ineficiência econômica a impede de estar no território ideal.

Podemos inferir que as UPPs caracterizem-se apenas como uma política de segurança pública, a qual é diretamente relacionada ao controle social de um determinado grupo e sobre um território específico, em detrimento de políticas públicas de segurança, onde há um investimento integral nas ações referente à educação, habitação, lazer, trabalho etc. Seguindo essa lógica, a segurança pública deriva da efetivação de direitos diversos. Não obstante, esta tem sido tomada como homônimo de ordem, culminando em um processo de militarização da segurança, baseada no modelo de apartheid.

Segundo Malaguti, a segurança pública só existe quando decorre de um conjunto de projetos públicos e coletivos capazes de gerar serviços, ações e atividades no sentido de romper com a geografia das desigualdades no território usado, caso contrário, o que ocorre é um controle truculento da população pauperizada.

É histórica a forma como as elites políticas brasileiras restringem o direito à cidade a um determinado segmento. Pires, Ribeiro e Kant (2011) ressaltam que, diferentes entre si, esses segmentos instituem, de acordo com princípios que hierarquizam os indivíduos por "status", uma desigualdade espacialmente definida, embora heterogênea, na falsa dicotomia do "morro" e do "asfalto", não concebendo partilhar com sujeitos dos demais segmentos sociais uma ordem onde tenham prevalência direitos e deveres iguais, uniformes e universalistas.

Para os autores, na perspectiva de igualdade por semelhança e da desigualdade da diferença, encontra-se uma justificativa para legitimar a implementação de políticas públicas territorial e socialmente desiguais. Sendo assim, quando essas políticas não são produzidas e aplicadas para a sociedade de forma universal, mas para setores específicos, sua legitimidade estará sujeita e será sempre avaliada conforme os interesses particulares de uma determinada classe, mas nunca como um serviço público garantidor de direitos universais.

Marx aponta a existência de uma contradição fundamental entre os "direitos do homem" e a realidade da sociedade capitalista. Para o pensador, a insistência da burguesia sobre os "direitos do homem" não passa de um postulado legalistaformal e, em última instância, sem conteúdo.

O argumento de Marx, segundo Mészáros (1993), é que a objeção "abstrata", não é apenas um traço da teoria jurídica, mas uma contradição insolúvel da própria estrutura social. As teorias burguesas defendem de maneira abstrata os direitos do homem. Por um lado, a burguesia defende a igualdade de direitos apenas no âmbito formal, por outro trabalham alienando a população quanto aos seus direitos, tratados como benesse. Dessa forma, contraditam e invalidam efetivamente esses mesmos direitos que pretendem estabelecer.

Ao mesmo tempo em que ouvimos os governantes ressaltando o direito que moradores de favelas têm de viverem livre da imposição do tráfico, observamos que ao analisarmos o conjunto dos direitos, veremos neles suas restrições. A "efetivação" e a "garantia" de parte desses direitos só se dão quando é conveniente ao capital. Além disso, não há uma participação dos moradores quanto as modificações ocorridas, tampouco priorizam as reais necessidade dos moradores, como 
aponta a reportagem da "EBC notícias"3 que trata de um morador da Providência, o qual teve sua casa removida pela prefeitura para a construção de um plano inclinado em seu bairro: "Um plano inclinado e um teleférico não suprirão as necessidades da nossa comunidade. Não temos nem saúde nem educação de qualidade na área, disse." (EBC notícias, 19/09/13)

Cabe observarmos que uma das características da implantação da UPP foi marcada pela falta de participação da população diretamente afetada, ocorrendo em alguns momentos de forma arbitrária e desconsiderando o que os moradores pensam sobre as mudanças. Em suma, grande parte das decisões ocorrem de "cima para baixo", sem um diálogo com os moradores.

Presencia-se nas favelas "pacificadas", dentre outras situações, o capitão da polícia determinando, por exemplo, qual é a atividade cultural mais pertinente para aquele espaço. Segundo o capitão Glauco, então comandante da UPP do Morro da Providência: "todo baile funk tem envolvimento com o tráfico. Apesar de ser uma cultura popular, a população ainda não está preparada para isso. No futuro, quando estiverem conscientizados, escutando música clássica, música popular brasileira, conhecendo outros ritmos, outras culturas, a gente até pode autorizar, mas hoje não". O termo "conscientizado" é um eufemismo para pontuar a necessidade de reeducação e disciplinamento daquela população.

Como enfatiza Malaguti, "presenciamos a gestão cotidiana dos pequenos gestos, do ir e vir, do lazer, enfim a vida dos pobres no Rio de Janeiro é parte desse grande movimento econômico, político e estratégico" (Malaguti, 2011, p.24). Nesse projeto de cidade, a polícia é tida como um ator privilegiado da reordenação física e moral das favelas. Como aponta a reportagem ${ }^{4}$ de Mauro Ventura ${ }^{5}$ em entrevista ao comandante-geral da PM: "Esse troço de UPP é sensacional. Apontou uns garotos: Era tudo do tráfico, mas nenhum fichado. Usavam cordão de ouro, cabelo amarelinho. Agora, pararam de pintar, tiraram cordão e até o andar mudou. Estão empurrando carrinho de mercado, todos trabalham".

A afirmação do coronel acima deixa em evidência a ideia de que as UPPs trazem o disciplinamento dos corpos. Assim como a ausência do pai não resulta em uma boa criação, a ausência da lei resulta em corpos indisciplinados. Para Guerra Filho, "o significante Pai é equivalente ao significante Lei” (Apud Batista, 2010, p.8).

A figura do pai é reciclada em lei, ou seja, a lei passa a ser figurada como pai. Batista (2010) faz uma análise histórica sobre a figura do pai, apontando que desde a antiguidade o pai dispunha de um feixe de poderes. Segundo o autor:

"O pater podia privadamente encarcerar, pelo tempo que lhe aprouvesse, seus filhos; Podia açoitá-los; impor-lhe grilhões para o trabalho na lavoura; vendê-los e matá-los. Estes poderes atravessam, no direito romano, quase incólumes, os períodos chamados antigo e clássico, para, na época helênica, serem restringidos pela perspectiva argumentativa da correção e disciplina" (Batista, 2010, p.9)

A exposição acima, nos remete a fala de um coronel sobre um conflito no Morro do Turano em agosto de 20116: "faz parte de um processo de reeducação dos moradores para uma nova ordem". A lei como pai tem um caráter de disciplinar/civilizar as pessoas que anteriormente não viviam sob a forma de lei/disciplina.

Confirmando essa assertiva Neri ressalta:

"O enfraquecimento da figura paterna conduziria à perda de referências e disseminação de comportamentos transgressivos às leis, gerando o aumento da violência e da criminalidade. Ao demandar a restauração da lei do pai, deixa no ar um pedido por mais ordem e mais limites, fazendo eco, desse modo, aos discursos repressivos provenientes de outros setores da sociedade." (Neri, 2010, p.159) $10 / 10 / 2013$

4 Reportagem utilizada no texto "O alemão é mais complexo" - escrito pela socióloga Vera Malaguti Batista

5 O Globo, Rio de Janeiro, 09 jan. 2011. Revista de Domingo, p.6.

$6 \quad$ Agência de Notícias da Favela, 24 de Agosto, 2011. 
A partir do exposto, consideramos que o discurso da "pacificação" vem com um sentido de disciplinar a população da favela, uma vez que a população vivia sem lei, com uma "figura paterna fraca" ocasionando o aumento da violência nesses espaços "sem lei".

Há uma demanda por mais poder punitivo, especialmente quando se trata de favelas e bairros populares, tidos como local onde se "esconde" o principal causador de desordem e insegurança: o traficante. Como adverte Malaguti (2003), o mercado de drogas ilícitas havia propiciado argumentos para uma política de genocídio e violação dos direitos humanos entre as classes pauperizadas. Além disso, a autora acrescenta que o modelo bélico traz marcas no judiciário que, ao tratar o suspeito ou condenado como inimigo, tolera violações de direitos e reifica os preconceitos contra as garantias constitucionais.

Machado (2008) adverte que o ator típico da violência urbana tem sido identificado como o traficante de drogas, tendo em vista que, o crescimento do tráfico tem sido o responsável pela alteração da "normalidade". Os traficantes são considerados um tipo de portador da violência urbana porque sua atividade exerceria sobre a categoria analisada uma ação centrípeta.

Vale ressaltar, como analisa Machado (2010), que o fato dos "territórios da pobreza" serem o foco da violência policial e criminal, associado ao tráfico de drogas não tem qualquer relação com a conduta dos moradores ou com o próprio fato desses locais serem o lugar de comercialização de drogas ilícitas. Para sustentar a afirmação, o autor destaca dois elementos relevantes: o primeiro refere-se ao fato de que as linhas de comando da cadeia produtiva estão fora das favelas e do território nacional. O segundo aspecto é explicado pelo fato da favela ser apenas o território onde ocorre o consumo final das drogas, a localização física da produção e negociação das drogas não se restringe a essas áreas, que respondem pela maior visibilidade do tráfico. A facilidade para a implantação desse comércio ilegal nessas áreas, como já apontamos, se dá devido à presença inócua do Estado por meio de políticas públicas.

O crime organizado, como analisa Zaffaroni (2007), foi um pseudoconceito inventado pelo jornalismo e que tem sido utilizado para habilitar e dar mais legitimidade ao poder punitivo. A figura do traficante é transformada - com êxito pela mídia - em inimigo interno perdendo todas as suas garantias constitucionais, e, consequentemente sua condição de pessoa, fortalecendo os sistemas de controle social aprofundando seu caráter letal.

Para Zaffaroni, o conceito de inimigo introduz a dinâmica da guerra no Estado de direito, colocando-se como exceção à regra. Tendo em vista, como afirma o autor, que o critério utilizado para medir a periculosidade de um indivíduo se baseia no campo da subjetividade de quem exerce o poder, essa "nomeação" de um ente perigoso incorrerá inevitavelmente no Estado absoluto.

Menegat (2005) aponta que o BOPE age nas favelas como se estivesse em meio a uma guerra civil, que se configura como crise de legitimação do Estado. Sendo assim, o autor constata que, se os dissidentes ao pacto regulador cresceu e se armou - pode-se afirmar que essa é, ao menos, o motivo que leva ao adjetivo "organizado" acrescido ao crime e estimulando uma sensação generalizada de medo e insegurança - vale questionar qual ordem buscam estabelecer, tendo em vista que a desordem atual indica a impossibilidade de continuidade da antiga ordem.

De acordo com Zaffaroni (2007), o poder punitivo desde a sua origem se fortaleceu por meio da imposição do medo. Malaguti faz uma interessante análise sobre a necessidade de propagação do medo para a legitimação de políticas autoritárias. Para a autora o medo tem um impacto difusor na vida social e política, apontando que o medo coletivo desempenhou um papel fundamental na formação da sociedade urbana: "o medo se transfigura em sentimento, em afeto, em política econômica, em projetos de lei, em fragmentos discursivos, em cenários, em políticas sanitárias".

A autora ressalta que no Brasil a difusão do medo e do caos tem a funcionalidade de dar respaldo às estratégias de neutralização e disciplinamento da classe empobrecida. O espraiamento dessa sensação é necessário para a implantação de políticas de lei e ordem. Nesse sentido, Malaguti (2003) aponta que a hegemonia conservadora trabalha com a propagação do 
medo como mecanismo indutor de políticas autoritárias de controle social e nessa missão, temos a mídia como principal fonte de difusão:

\begin{abstract}
"As transformações tecnológicas e o controle da indústria da mídia resultariam numa tendência à homogeneização universalizante e reducionista da subjetividade. É por isso que afirmamos que a grande política social da contemporaneidade neoliberal é a política penal. A qualquer diminuição do seu poder os meios de comunicação de massa se encarregam de difundir campanhas de lei e ordem que aterrorizavam a população e aproveitam para se reequiparar para os 'novos tempos'. Os meios de comunicação de massa, principalmente a televisão, são hoje fundamentais para o exercício do poder de todo sistema penal, seja através de novos seriados, seja através de fabricação de realidade para produção de indignação moral, seja pela fabricação de estereótipo do criminoso" (Malaguti, 2003, p.33).
\end{abstract}

Há uma necessidade do projeto neoliberal de capilarizar e tornar onipresente o poder punitivo para o controle penal dos contingentes humanos que ele próprio marginaliza (Batista, Apud Malaguti, 2003). O medo torna-se algo concreto, transformando-se assim em discursos, em teorias criminológicas baseadas no senso comum que reafirmam as políticas de extermínio.

Zaffaroni (2007) destaca que nas sociedades mais desfavorecidas pela globalização, a exclusão social constitui o principal problema, uma vez esta costuma ser controlada via neutralização dos conflitos, aprofundando as contradições internas. O discurso do ódio ao "inimigo" é funcional para reproduzir conflitos entre os excluídos, tendo em vista que os criminalizados, os vitimizados e os policizados são dessa mesma classe, enfraquecendo sua capacidade de resistência e oposição a ordem estabelecida. A polarização da riqueza nessas sociedades deteriorou as classes médias, assim seus discursos pautam-se por um caráter mais autoritário e truculento por receio de passarem a pertencer a classe pauperizada.

Para o autor, na medida em que a riqueza se polariza, o recrudescimento de práticas criminalizadoras tornam-se cada vez mais aceita e aplaudida, com uma discurso simplista que clama pela vingança pura e simples, pois parece compensar a segurança perdida por causa da globalização e da perda da coesão.

Ainda segundo Zaffaroni, cria-se uma ilusão de que a segurança será garantida sancionando leis que reprimam acima de qualquer medida os raros marginalizados tomados individualmente e aumentando a truculência policial, legitimando todo e qualquer tipo de violência, inclusive contra aqueles que se colocam contra o discurso do autoritarismo. A consequência dessas mensagens é o reforço de que um mundo em desordem poder ser "concertado" com disciplina imposta por meio da repressão indiscriminada.

Diante da funcionalidade e da facilidade desse mecanismo os políticos se apoderam desse discurso e aquele que pretende confrontar o mesmo é desqualificado e marginalizado dentro de seu partido e na sociedade como um todo:

"Esse discurso se impõe ao Estado porque exige a alienação dos políticos, que devem optar entre aderir à publicidade da repressão e ficar na moda (tornar-se $\mathrm{cool}$ ) ou ser afastados pelos competidores internos de seus próprios partidos, que aproveitariam o flanco débil de quem se mostra antiquado e impopular, ou seja, não cool." (Zaffaroni, 2007, p.78)

Assim, vemos a imposição de um discurso único do novo autoritarismo, denominado pelo autor de autoritarismo cool, atingindo diretamente a democracia e as garantias constitucionais.

\title{
3.3 Uma aproximação das UPPs sob a luz foucaultiana
}

Durante a época clássica, segundo Foucault (2010), o corpo foi descoberto como objeto e alvo do poder, reconhecido como aquele que se pode manipular, treinar, obedecer e ter suas forças multiplicadas. 
Ao citar o livro "O Homem-máquina", Foucault aponta a docilidade de um corpo que pode ser submetido, utilizado, transformado e aperfeiçoado. A disciplina impõe sutilmente a sujeição da força sob a imposição da docilidade, tornando-se fórmulas gerais de dominação.

Foucault aponta que o momento histórico das disciplinas é quando nasce uma arte do corpo humano capaz de torná-lo obediente na mesma proporção de sua utilidade, formando então uma política das coerções que se configura como um trabalho sobre o corpo, uma manipulação cuidadosa de seus elementos, de seus gestos e comportamentos. A coerção disciplinar estabelece no corpo humano o elo coercitivo entre uma aptidão aumentada e uma dominação acentuada.

No processo de disciplinamento, o corpo humano entra numa maquinaria de poder que o esquadrinha, o desarticula e o recompõe, aumentando a força do corpo na sua utilidade econômica e diminuindo, simultaneamente, essas mesmas forças no que se refere a obediência, potencializando as hierarquias sociais e as relações de poder. Não se desenvolve a potencialidade do sujeito na sua autonomia, no seu pensamento criativo, na sua capacidade de questionamento. A disciplina usa a força da forma como lhe é útil e inverte a potência que poderia resultar desse estímulo, transformando-a numa relação de sujeição estrita (Foucault, 2010).

Contudo, vale ressaltar como adverte o autor, que esse tipo de controle sobre o corpo não deve ser entendido como uma descoberta súbita, mas como uma multiplicidade de processos que se recordam e se repetem apoiando-se uns sobre os outros. Podemos encontrar esse método em funcionamento nas escolas, nos hospitais e no espaço militar. Sempre correspondendo às exigências de uma determinada conjuntura histórica.

Atualmente podemos encontrar esse tipo de controle na atual conjuntura da cidade do Rio de Janeiro. Observamos a população como um todo sendo disciplinada para se adaptar ao novo formato de cidade. Esse controle da vida social, marcado por um processo de disciplinamento, tem sido mais intensificado no cotidiano dos moradores das favelas pacificadas. Corpos com sua capacidade de transformação são domesticados, disciplinados de forma utilitária para uma nova ordem. Para que esse novo projeto de cidade se efetive, são necessários corpos disciplinados, impostos por uma relação de docilidade-utilidade.

Assim como ressalta Sánchez (2001), que para essa nova proposta de ordem urbana se efetive, é necessário a "fabricação de uma cidadania" que se pretende ajustá-la ao projeto de cidade, com vistas a garantir uma ordem social. Nesse sentido, a disciplina funciona de forma a "fabricar" indivíduos que se adaptem a essa cidadania fabricada, sendo ela (a disciplina) a técnica específica de um poder que toma os indivíduos concomitantemente como objetos e como instrumentos de seu exercício.

Ao mesmo tempo em que o trabalhador desenvolve suas potencialidades no processo produtivo há também uma dominação acentuada sobre esses corpos, onde o trabalhador não se reconhece em seu produto apesar de ter desenvolvidas suas capacidades produtivas. A disciplina preocupa-se com pequenas coisas dotadas de um grande poder de difusão (Foucault, 2010).

Nesta direção, à ideia de que as UPPs proporcionam a integração entre favela e asfalto é falaciosa, tendo em vista que a disciplina por vezes impõe a cerca, corroborando o discurso e a prática do secretário de segurança pública. Segundo Foucault (2010), é necessário a demarcação de um espaço heterogêneo a todos os outros e fechado em si mesmo. Locais onde o disciplinamento ocorre de forma mais acentuada, com o objetivo de manter aquele grupo em ordem e em disciplina:

"Importa estabelecer as presenças e as ausências, saber onde e como encontrar os indivíduos, instaurar as comunicações úteis, interromper as outras, poder a cada instante vigiar o comportamento de cada um, apreciá-lo, sancioná-lo, medir as qualidades ou os méritos. Procedimento, portanto, para conhecer, dominar e utilizar." (Foucault, 2010, p.138).

Nesse sentido, o referido discurso de integração com a implantação da UPP é retórico, posto que é necessário manter aqueles moradores naquele espaço exercendo sobre eles um controle específico. "Importa distribuir os indivíduos num espaço 
onde se possa isolá-los e localizá-los; mas também articular essa distribuição sobre um aparelho de produção que tem suas exigências próprias" (Foucault, 2010, p.140). A funcionalidade dessa distribuição funciona assim como a disciplina nos quartéis, impedindo a pilhagem e a violência; acalmar os habitantes que suportam mal as tropas de passagem e evitar os conflitos com as autoridades civis. São corpos que tem suas potencialidades de contrariar o estabelecido e por isso, precisam passar por um disciplinamento minucioso.

A citação acima nos faz lembrar do muro construído pela prefeitura em parceria com o governo Estadual em 2010, na Linha Vermelha, isolando o bairro Maré da via expressa. A justificativa para a construção do muro foi para a proteção dos moradores quanto aos barulhos produzidos pelos carros que circulam na Linha Vermelha. Entretanto, de acordo com o histórico de segregação urbana do Rio de Janeiro, podemos afirmar que a construção do muro tem como objetivos: "ocultar" o bairro dos turistas, uma vez que a via expressa é caminho do Aeroporto Internacional para a Zona Sul, onde também passarão as comitivas dos países que vão participar da Copa de 2014 e da Olimpíada em 2016, bem como isolar os moradores do restante da cidade. Assim como ocorre no processo de disciplinamento das fábricas, é preciso isolar e localizar essa massa, neutralizar seus inconvenientes e dominar a força de trabalho. Para Batista $(2008)^{7}$ esses muros configuram-se como dispositivos arquitetônicos de controle penal punitivo, aumentando a discriminação e a segregação. Para o autor: "Num mundo onde, curiosamente, não há fronteiras para as mercadorias que integram um projeto hegemônico, mas há fronteiras para seres humanos" (p.141 - 142).

Quando analisamos o projeto de "pacificação" sob a perspectiva de Foucault no que se refere a sociedade panóptica, podemos encontrar algumas semelhanças com o contexto atual das favelas do Rio de Janeiro e as formas de controle utilizados nas cidades contaminadas por doenças epidêmicas no fim do século XVII.

Algumas medidas eram tomadas quando se declarava a existência de uma doença epidêmica, contudo quando a cidade era tomada pela lepra utilizavam-se modelos de exclusão, já na peste suscitava esquemas disciplinares. Podemos inferir que a "doença" no atual contexto se configura pela condição de pobreza e marginalidade social de parte da população.

A cidade pestilenta era tratada por meio de um policiamento espacial estrito, cada rua é colocada sob uma autoridade do que a vigia, os que circulam nessa cidade são selecionados de acordo com o lugar que ocupam na localidade: "Só circulam os intendentes, os síndicos, os soldados da guarda (...) espaço recortado, imóvel, fixado. Cada qual se prende a seu lugar. E, caso se mexa, corre perigo de vida por contágio ou punição" (Foucault, 2010, p.186). A inspeção nessa cidade funciona constantemente, com corpos de guardas nas portas e em todos os bairros para fazer com excelência a obediência do povo, bem como vigiar as desordens, roubos e pilhagens. Cotidianamente, o síndico passa na rua que é o responsável e pede que cada integrante das casas se coloquem na janela, com o objetivo de verificar se nessas casas estão escondidos mortos ou doentes. $\mathrm{O}$ controle está alerta em toda parte: “Um corpo de milícia considerável, comandado por bons oficiais e gente de bem” (p.186).

Tal vigilância se apoia em um sistema de registro, onde relatórios são entregues para as autoridades. Nesses relatórios se estabelece o papel de cada habitante, onde se anotam todos seus dados, tudo o que é observado na vigilância é registrado. Cada indivíduo é constantemente localizado, examinado e distribuído entre os vivos, os doentes e os mortos.

Nesse caso, podemos relacionar os dispositivos disciplinares dessa cidade com a forma de "pacificação" em algumas favelas do Rio de Janeiro, uma vez que as cidades trabalhadas pelo autor, bem como as favelas pacificadas são marcadas por uma organização aprofundada de vigilância e controle. O pestilento se submete a um policiamento tático e meticuloso, assim como o morador de área pacificada, sob o qual é exercido um constante controle por meio do policiamento, com a submissão dos moradores as ordens impostas.

7 Nilo Batista participou da Conferência Internacional "Dilemas da Humanidade: Diálogos entre Civilizações" como comentador da mesa "A Desigualdade social crescente, as classes sociais e as formas de organização social" (2008). 
No que diz respeito a cidade leprosa, os dispositivos disciplinares sob ela imposto, é marcado por modelos de exclusão: "O leproso é visto dentro de uma prática de rejeição, do exílio-cerca; deixa-se que se perca lá dentro como numa massa que não tem muita importância diferenciar.” (Foucault, 2010, p.188).

Nesse caso, podemos pensar nessa cidade pela perspectiva das favelas não pacificadas, onde o morador é visto com rejeição tendo em vista que nesse novo contexto de cidade, este não tem qualquer funcionalidade, logo é isolado, sem qualquer importância diferenciá-lo.

Vale ressaltar, que ambas as formas acima expostas exercem poder sobre os sujeitos, de controlar suas relações e seus modos de vida, são esquemas diferentes, mas não incompatíveis. Como afirma Foucault (2010), a cidade pestilenta é marcada pelo bom treinamento, já a cidade leprosa pelo grande fechamento. São duas formas de exercer poder sobre a população e de controlar suas relações e que em algum momento estabelecem uma relação simbiótica; "pestilentam-se" os leprosos, impondo aos excluídos o disciplinamento individualizante.

A cidade pestilenta, segundo Foucault, é a utopia de uma cidade perfeitamente governada. Assim, para ver funcionar suas disciplinas, os governantes sonhavam com o estado de peste. Vemos a atualidade do exposto, quando observamos que a profusão do medo, isolamento e controle induzem a sociedade a clamar por mais punição e vigilância, fortalecendo assim, o recrudescimento de políticas de controle disciplinar.

Assim como ressalta Neri e Cavalcanti (2008) novas tecnologias de vigiar, controlar e punir transforma a própria sociedade em uma prisão sem portas, compondo uma combinação perversa dos dispositivos da sociedade disciplinar e dos dispositivos da sociedade de controle.

\section{Considerações Finais}

Presenciamos um intenso investimento dos gestores do Rio de Janeiro na recuperação da imagem objetivando a superação do estigma de desorganização, violência e pobreza. A preocupação dos governantes não está nas mudanças objetivas da cidade, com vistas a melhoria das condições de vida da população, mas nas ações que visem recuperar a imagem de uma "cidade maravilhosa".

A cidade vem assumindo fortemente uma identidade mercadológica com contornos empresariais. Para a produção desse novo espaço, operam diferentes agentes e interesses combinados, dentre eles governos locais, atores hegemônicos com interesses específicos, bem como agências multilaterais de caráter internacional e ação global, que trabalham como centros de pensamento, difusão e financiamento de políticas públicas.

A cidade, tratada como mercadoria, passa a ser pensada de forma a atender as necessidades de um tipo específico de consumidor, sendo eles o capital internacional, visitantes e usuários que possam pagar. Tem-se então que a mercadoria cidade tem um grupo muito específico, sobretudo por se tratar de uma mercadoria de luxo. Sendo esta uma mercadoria de luxo, todos aqueles que não estão dentro dos grupos de consumidores e que podem "sujar" essa imagem de cidade - os "indesejáveis" são tratados pelo viés penal.

Os investidores não "abrem mão" de uma clara e decisiva intervenção estatal, desde que voltada para os interesses constituídos e dominantes no mercado. Assim, a parceria público-privada assegurará que os interesses do mercado estarão assegurados no processo de planejamento e decisão. Desse modo, vemos que o interesse particular se sobrepõe a coisa pública, ao interesse de todos.

Nesse contexto, as Unidades de Polícia Pacificadora surgem como mais uma das inciativas tomadas para a transformação dessa cidade em commodities com vistas a atender esse público. É necessária a venda de uma cidade que ofereça segurança para investimento do grande capital. Dessa forma, o objetivo do programa das UPPs, iniciado em dezembro 
de 2008, é diminuir a sensação de insegurança, eliminando os conflitos armados em áreas de alta renda que tanto atraem seus consumidores.

A relação entre a população e instituição policial, quando vista a partir do legado histórico, permite-nos identificar que elementos característicos de nossa sociedade contemporânea sempre estiveram presentes na realidade brasileira, dentre eles o arbítrio do poder público frente aos segmentos populares. O projeto de pacificação, assim como aponta Malaguti, não é algo novo na história. As UPPs basearam-se no modelo de Medellín e faz parte de um arsenal de intervenções urbanas previstas para regiões ocupadas militarmente no mundo.

Diante das experiências atuais vivenciadas nas favelas "pacificadas" e não "pacificadas", fica evidente que esse projeto de pacificação objetiva disciplinar os moradores da favela para esse novo contexto de cidade. Assim, ao identificarmos a aparência e a ultrapassarmos, desvendando a essência, pode-se ver que tais ocupações evidenciam o controle militarizado da vida social desses espaços, marcado por um forte estigma de que os territórios favelados são determinados por uma desorganização familiar e comunitária, dando legitimidade a referida ocupação. Há um equívoco na argumentação de que a favela se configura como um espaço dominado pela irracionalidade, como se não houvesse regras de sociabilidade estabelecidas entre os moradores, sendo necessária assim a intervenção de um agente externo para o controle dessa população.

O processo de pacificação nas favelas cariocas tem se baseado numa gestão penal da pobreza enfocando em políticas criminais, acentuando o Estado de polícia com a retração do Estado social. O que presenciamos é o controle social da classe pauperizada e uma carência no investimento em serviços públicos. As favelas, vistas como lugar das “classes perigosas”, são tratadas por meio desse projeto como um local que precisa ser dominado, civilizado e pacificado. A polícia vem com a imposição de um novo modelo cultural, em detrimento do saber cultural já construído entre os moradores.

Assim, a experiência da pacificação não se configura de fato numa garantia de direitos para a população moradora de bairros populares e favelas, esta traz apenas uma falsa sensação de segurança. A violência persiste nesses espaços e sua persistência se mantem em um exercício rigoroso sobre esse determinado grupo. Há uma substituição de quem impõe o poder, as armas mudam de mão, mas a violência se mantem nesses locais com a manutenção da imposição armada, sem qualquer melhoria nas condições de vida dessa população.

A segurança pública tem sido tratada pelos governantes como homônimo de ordem e não como uma ação integrada de diferentes políticas públicas, com vistas à de romper com a desigualdade nos diferentes territórios. Torna-se insustentável o controle realizado pela força punitiva do Estado sobre a classe pauperizada, dessa forma é necessário o investimento em uma política pública de segurança que se compõe pelo somatório de diferentes áreas, alcançando uma diminuição cada vez maior do poder punitivo.

Além disso, faz-se necessário o resgate com a população moradora de bairros populares e favelas, dominados pelos diferentes poderes constituídos, que tais lugares já foram diferentes do que esta posto e que é possível reconstruirmos um espaço diferente. Assim como aponta Malaguti (2003): "para romper o silêncio, desnaturalizar o extermínio dos pobres, desbanalizar o olhar dos nossos tempos, temos que recorrer à memória, a história de nossa cidade. (...) E é na memória viva dessa cidade que pretendemos entender o presente pelo passado" (p.120).

É possível pensarmos nas dimensões positivas desses territórios e vermos perspectivas futuras. Nesse sentido, o resgate da história local por meio da memória buscando romper com o silêncio, trabalhar com a desnaturalização das arbitrariedades e a valorização do espaço para além de um lugar violento pode permitir ao morador observar que não é necessária a presença do tráfico de drogas, tampouco um braço armado interferindo no lugar e regulando a relação entre eles, possibilitando possíveis transformações no território a partir da mobilização destes.

Quanto as pesquisas futuras, objetiva-se analisar os impactos da instalação das UPPs nos espaços favelados após a realização dos mega eventos, uma vez que os intensos investimentos na área foram reduzidos consideravelmente. Deste modo, 
Research, Society and Development, v. 10, n. 1, e24410111707, 2021

(CC BY 4.0) | ISSN 2525-3409 | DOI: http://dx.doi.org/10.33448/rsd-v10i1.11707

pretende-se analisar o legado deixado nos territórios ditos "pacificados", além de problematizar a presença do Estado apenas como agente da segurança pública.

\section{Referências}

Batista, N (2010). A lei como pai. Passagens - Revista internacional de história, (2), 20-38.

Bretas, M. L (1998). A polícia carioca no império. Revista Estudos Históricos. (12), 219-234.

Dornelles, J. R. (2001). Entre Pombos e Falcões. Conflito e Segurança Pública no Rio de Janeiro. Tese de doutorado, Universidade Federal do Rio de Janeiro, Rio de Janeiro, RJ, Brasil.

Foucault, M. (2010). Vigiar e Punir: nascimento da prisão. Ed. Vozes.

Kosik, K. (1976). Dialética do concreto. Trad. Célia Neves e Alderico Toríbio. Paz e Terra.

Machado, L. A. (2008). Violência urbana, sociabilidade violenta e agenda púbica. In: Machado da Silva, L. A. (Org.). Vida sob cerco: violência e rotina nas favelas do Rio de Janeiro. Rio de Janeiro: Nova Fronteira.

MalagutI, V. B. (2003). O medo na cidade do Rio de Janeiro: dois tempos de uma história. Ed Revan.

Malaguti, V. B. 2011. O alemão é muito mais complexo.

Marx, K.(1979). A Ideologia Alemã. In IANNI, O. (org.) Karl Marx - Sociologia. Ática.

Marx, K. \& Engels, F (2008). O manifesto do partido comunista. expressão popular.

Minayo, M. C. S. (2011). Pesquisa social: teoria, método e criatividade. Vozes.

Maricato, E (2013). É a questão urbana, estúpido. In.: Maricato, E. (org.). “Cidades rebeldes: passe livre e as manifestações que tomaram as ruas do Brasil.” Ed. Boitempo.

Menegat, M (2005). Quem decidiu essa guerra em que todos morremos? In: MENEGAT, M. \& NERI, R. Criminologia e Subjetividade. Editora: Lumen Juris.

MészároS, I. (2008). A desigualdade social crescente, as classes sociais e as formas de organização social. In: MENEGAT, M.; BERING, E. R. E FONTES, V. Dilemas da humanidade: diálogos entre civilizações. Contraponto.

Neri, R. \& Cavalcanti, M. (2005). Novas Tecnologias de Vigiar e Punir. In: MENEGAT, M; NERI, R. Criminologia e Subjetividade. Editora: Lumen Juris.

Neri, R. (2010). Uma Reflexão sobre a Concepção de Lei na Psicanálise: O Pai como Lei e a Lei como Pai. In: Abramovay, P. V. \& Vera M. (org.)"Depois do grande encarceramento". Instituto carioca de criminologia/Revan.

Pires, L.; Ribeiro, L. C. \& Kant, R. de L (2011). Entre a guerra e a pacificação: Paradoxos da administração institucional de conflitos no Rio de Janeiro, Rio de Janeiro,

Sassen, S (1993). A Cidade Global. In: Lavinas, Lena; Carleial, Liana; Nabuco, Maria. (org.). "Reestruturação do espaço urbano e regional no Brasil”. Ed. Hucitec.

Sánchez, F (2001). A reinvenção das cidades na virada de século: agentes, estratégias e escalas de ação política. Revista Sociologia Política.

Zaffaroni, E. R. (2007). O inimigo no direito penal. Revan. 